\title{
Admission Hypothermia Among Neonates Presented to Neonatal Intensive Care Unit
}

\author{
Akter $\mathbf{S}^{1}$, Parvin $\mathbf{R}^{2}$, Yasmeen $\mathbf{B H N}^{3}$ \\ ${ }^{1}$ Dr. Shaheen Akter, MBBS, MD, FCPS (Neonatology), \\ Associate Professor and Head of NICU, Enam \\ Medical College, ${ }^{2}$ Dr. Rubiya Parvin, MBBS, MD, \\ FCPS(Paediatrics), MD(Neonatology), Assistant \\ Professor (Neonatology), Institute of Child and \\ Mother Health, ${ }^{3}$ Dr. B.H. Nazma Yasmeen, MBBS, \\ MD, Associate Professor and Head of Department \\ of Paediatrics, Northern Medical College. Dhaka, \\ Bangladesh.
}

\section{Introduction}

$\mathrm{T}$ he neonates are most sensitive to hypothermia (axillary temperature less than $36.5^{\circ} \mathrm{C}$ or $97.7^{\circ} \mathrm{F}$ ), during the first 24 hours and early days of life $\mathrm{e}^{1,2,3}$. Reports from different Asian and African developing countries show that neonatal hypothermia is common and has been regarded as a major contributor cause of significant morbidity $1,2,3,4$.

In developed countries, the incidence of neonatal hypothermia is mostly confined to transported out born, premature and LBW infants. In developing countries this condition is highly prevalent among all neonates irrespective of gestational age and birth weight ${ }^{5}$.

Neonatal hypothermia on admission to NICU is a common morbidity in developed, tropical and subtropical developing countries ${ }^{1,6,7}$. The temperature on admission to nursery reflects the efficacy and level of newborn care from the time of birth, the stay in labor ward or home, and the transfer to nursery ${ }^{8}$.

In Bangladesh $85 \%$ of the women deliver baby at home where minimal attention is given to thermal protection ${ }^{9}$. Moreover there are some harmful traditional practices like early bathing or delayed cord clamping until the placenta is delivered ${ }^{10}$. Even in hospitals, health personnel are not always aware of the importance of keeping babies warm by simple methods such as drying and wrapping immediately after birth, encouraging early breastfeeding and keeping newborns in close

\section{Address for correspondence \\ Dr. Shaheen Akter \\ 1391, East Shewrapara \\ Mirpur, Dhaka -1216, Bangladesh \\ Email: haheenssr7@yahoo.com}

\begin{abstract}
Introduction: In developing countries, thermal protection of the newborn is not properly addressed. Neonates presented to Neonatal intensive care unit (NICU) for admission with various problems are frequently found to be hypothermic. The objective of this study was to determine the incidence and associated risk factors for neonatal hypothermia on admission to NICU. Materials and Methods: This was a prospective observational study carried over a period of three years at Enam Medical College and Hospital (EMCH) among the newborns admitted to NICU. Hypothermia has been defined as axillary temperature $<36.5^{\circ} \mathrm{C} \quad\left(<97.7^{\circ} \mathrm{F}\right)$. Temperature was measured at admission. Data were collected regarding perinatal and socio economic factors. Bivariate and multivariate analysis has been done to see the association of risk factors. Result: A total of 2310 babies between 0 and $680 \mathrm{~h}$ of age (mean $43 \pm 12$ hours) were studied. Thirty four percent (785) of the neonates had hypothermia. Mean gestation was $34 \pm 3$ weeks and $42.5 \%$ were inborn. Significant determinants of neonatal hypothermia at admission included factors like preterm $(p=0.03)$, low birth weight $(p=0.005)$, normal delivery $(p=0.012)$, birth asphyxia $(p=0.001)$ below average socioeconomic status $(p=0.001)$ and long distance $(>10 \mathrm{~km})$ traveled by the neonate $(p=0.03)$. Independent variables are resuscitation at birth [ $p=.001$, Odds Ratio (OR), 2.43; Confidence Interval $(\mathrm{Cl}), 1.47$ to 4.00$],(p=0.001)$, age less than 24 hours ( $p=.02$; OR 2.25 ; $\mathrm{Cl}, 1.13$ to 4.47 ), low birth weight ( $p=0.03 ; \mathrm{OR}, 2.0 ; \mathrm{Cl}, 1.06$ to 3.82$)$, caesarean section(C/S) delivery ( $p=.006$; OR 1.35; $\mathrm{Cl}, 1.18-2.12)$ and below average economic status $(p=0.001 ; \mathrm{OR}, 2.76 ; \mathrm{Cl}, 1.56$ to 5.90). Conclusion: Incidence of admission hypothermia among neonates in our NICU was $34 \%$. Independent risk factors are resuscitation at birth, very low birth weight, C/S delivery, age less than 24 hours and poor socio-economic condition. Proper thermal care should be provided for neonates both at home and hospitals.
\end{abstract}

Key words: Admission hypothermia, NICU

\section{How to cite this article?}

Akter S, Parvin R, Yasmeen BHN. Admission Hypothermia Among Neonates Presented to Neonatal Intensive Care Unit. J Nepal Paediatr Soc 2013;33(3):166-171. 
contact with their mothers. During resuscitation at birth, temperature maintenance is not taken care of. In case of home delivery, a sick neonate has to travel a long way to the hospital without any thermal protection during the transport.

Considering these information, it is evident that neonatal hypothermia is a serious health problem in Bangladesh both among those born at home and at different levels of hospitals. In our country, studies on neonatal hypothermia are few or unpublished. Studies on neonatal hypothermia will make us aware about the extent and severity of the problem in order to improve preventive intervention.

The objective of this study was to determine the incidence and associated risk factors for neonatal hypothermia on admission to NICU.

\section{Materials and Methods}

This was a prospective observational study conducted among the newborns admitted to NICU of Enam Medical College and Hospital (EMCH), from July 2009 to June 2012. EMCH is an undergraduate teaching Institute. The NICU provides specialist neonatal care for babies delivered in the maternity unit of the hospital and those referred to the hospital from other health facilities.

Hypothermia has been defined as axillary temperature $<36.5^{\circ} \mathrm{C} \quad\left(<97.7^{\circ} \mathrm{F}\right)$. Temperature was measured for 3 minutes in axilla with mercury in glass clinical thermometer with a temperature range of $34.4^{\circ}$ to $42.2^{\circ} \mathrm{C}\left(94^{\circ}\right.$ to $\left.108^{\circ} \mathrm{F}\right)$. We included all neonates admitted to NICU during the study period. The first temperature obtained in neonates at admission to the NICU from the labor ward or from outside the hospital was recorded as 'admission temperature' along with the date and time charted.Concerning newborns body temperature; they were divided into two groups of 'Hypothermic' and 'Non hypothermic' neonates.

Other data obtained from the neonates included the clinical diagnosis, age in hours, sex, body weight, estimated gestational age (EGA), place and mode of delivery, and resuscitation needed. Parent's socioeconomic status and the distance traveled to arrive at NICU were recorded. Regarding socioeconomic status monthly family income has been recorded. Family income less than 175 USD per month has been considered as below average, 175 to 350 USD per month has been considered as average and more than 350 USD per month as above average ${ }^{11}$.

\section{Data analysis}

Data managment and anlaysis was done using the Statistical Package for the Social Science (SPSS, version: 15.1). Comparative analysis of the variables was done between the "Hypothermic" and "Non hypothermic" groups. Data analysis for associations with admission temperature was initially explored with bivariate analyses between admission temperature and intrapartum variables, infant characteristics, and delivery room events. During bivariate analysis the categorical variables were tested with Chi square $\left(\mathrm{c}^{2}\right)$ and Fisher's exact test and for continuous variable Student's t test was done. Multivariate analysis (of the variables which were found to be significantly related with the occurrence of hypothermia) was done by Stepwise logistic regression analysis.

\section{Results}

A total of 2310 babies between 0 and $680 \mathrm{~h}$ of age (mean $43 \pm 12$ hours) were studied. Seventy seven percent (1779) of the neonates were admitted in $\leq 24$ hours of age. Among the study population $61.5 \%$ males and $38.5 \%$ were females with mean weight of $2246 \pm 460$ gram (range of $600-4500 \mathrm{gm}$ ).

The mean estimated gestational age (EGA) was $34 \pm 3$ weeks (24-43 weeks). Among them $56.5 \%$ were preterm and $43.5 \%$ were term babies. Fifty seven percent (1317 of 2310) was delivered by caesarean section(C/S). Majority of the neonates were outborn (44\% in other hospitals and $14.5 \%$ at home) and $42.5 \%$ were inborn. Among out born neonates (1328), 69\% traveled $\leq 10$ kilometer and $31 \%$ traveled $>10$ kilometer to reach to our hospital. Fifty nine percent neonates were from below average and rest from average and above average socio-economic status [table I].

In our study population, 785(34\%) neonates had hypothermia. The mean age (35 \pm 11 hours) of hypothermic babies was compared with the mean age $(54 \pm 5.6$ hours) of the babies with normal body temperature which was statistically significant $(p=$ 0.001).

The prevalence of hypothermia among babies in different groups of risk factors is shown in table II. Hypothermia occurred more commonly among babies who presented within 24 hours of birth compared to babies more than 24 hours of age on admission. It also occurred more commonly among preterm compared to term babies (EGA $34.4 \pm 4$ weeks vs $37.6 \pm 3$ weeks $p=0.03$ ), among low birth weight compared to normal weight babies ( $2015 \pm$ gram vs $2369 \pm 530$ gram, $p=0.005$ ), among babies born by caesarian section compared to those born normally $(p=0.012)$. Hypothermia also occurred more frequently among babies who needed resuscitation at birth $(p=0.001)$. Among the non clinical factors, below average socioeconomic status and long distance $(>10 \mathrm{~km})$ traveled by the neonate were 
significantly related with the occurrence of hypothermia $(p=.001$ and $p=.03$ consecutively). Sex of the neonate $(p=.34)$ and place of delivery $(p=.112)$ had no effect on hypothermia.

Risk factors revealed as significant on bivariate analysis were introduced into a logistic regression model (table III) as independent factors. The dependent variable was the presence of hypothermia. On logistic regression analysis, significant factors were resuscitation at birth $(p=0.001)$, age less than 24 hours $(p=.02)$, lowbirth-weight $(p=0.03)$, normal delivery $(p=.006)$ and below average economic status $(p=0.001)$. However, preterm birth, place of delivery, and distance traveled to reach the hospital were not found to be significant on multivariate analysis.

Table 1: Characteristics of the study population $(n=2310)$

\begin{tabular}{|l|c|c|c|}
\hline Parameters & Categories & Number & Percentage \\
\hline \multirow{4}{*}{ Weight (grams) } & $<1000$ & 60 & 02.6 \\
\cline { 2 - 4 } & $1000-1499$ & 315 & 13.5 \\
\cline { 2 - 4 } & $1500-2499$ & 948 & 41.0 \\
\cline { 2 - 4 } Gestational age (weeks) & $\geq 2500$ & 987 & 22.0 \\
\cline { 2 - 4 } & $\leq 32$ & 520 & 34.0 \\
\cline { 2 - 4 } & $33-<37$ & 785 & 43.5 \\
\hline \multirow{4}{*}{ Age at admission (Hour) } & $\geq 37$ & 1005 & 23.6 \\
\cline { 2 - 4 } & At birth & 545 & 53.6 \\
\hline \multirow{3}{*}{$\begin{array}{l}\text { Socio- economic } \\
\text { status }\end{array}$} & $\leq 24$ & 1234 & 09.4 \\
\hline \multirow{3}{*}{$\begin{array}{l}\text { Distance traveled } \\
\text { (Kilometer) }\end{array}$} & $>24-72$ & 217 & 13.4 \\
\cline { 2 - 4 } & Below average & 314 & 59.5 \\
\cline { 2 - 4 } & Average & 1374 & 31.5 \\
\cline { 2 - 4 } & Above average & 728 & 9.0 \\
\hline
\end{tabular}

Table 2: Comparison of the risk factors among Hypothermia and Non hypothermia groups

\begin{tabular}{|c|c|c|c|c|c|}
\hline \multirow[t]{2}{*}{ Variables } & \multirow[t]{2}{*}{$\begin{array}{c}\text { Categories } \\
\text { (Number of each) }\end{array}$} & $\begin{array}{l}\text { Hypothermic } \\
(785)\end{array}$ & $\begin{array}{c}\text { Non } \\
\text { Hypothermic } \\
(1525)\end{array}$ & \multirow[t]{2}{*}{$P$ value } & \multirow[t]{2}{*}{ OR(95\%Cl) } \\
\hline & & $\mathbf{N}(\%)$ & N (\%) & & \\
\hline \multirow{2}{*}{ Age(hour) } & $\leq 24(1779)$ & $656(37)$ & $1123(63)$ & \multirow{2}{*}{$.001^{*}$} & \multirow{2}{*}{$2.23(1.22-4.0)$} \\
\hline & $>24(531)$ & $129(24)$ & $402(76)$ & & \\
\hline \multirow{2}{*}{ Weight(kg) } & $<2.5(1323)$ & $514(39.6)$ & $809(60.4)$ & \multirow{2}{*}{$005^{*}$} & \multirow{2}{*}{$1.56(1.99-2.45)$} \\
\hline & $\geq 2.5(987)$ & $217(27)$ & $716(73)$ & & \\
\hline \multirow{2}{*}{ EGA(weeks) } & $<37(1305)$ & $486(37.3)$ & $819(62.7)$ & \multirow{2}{*}{$.03^{*}$} & \multirow[t]{2}{*}{$1.60(1.55-1.8)$} \\
\hline & $\geq 37$ (1005) & $299(30)$ & $706(70)$ & & \\
\hline \multirow{2}{*}{$\begin{array}{l}\text { Place of } \\
\text { delivery }\end{array}$} & Inborn (982) & $215(22)$ & $767(78)$ & \multirow{2}{*}{.112} & \multirow{2}{*}{$1.48(.85-2.58)$} \\
\hline & Out born (1328) & $570(43)$ & $758(57)$ & & \\
\hline \multirow{2}{*}{ Mode of delivery } & Normal (993) & $278(28)$ & $715(72)$ & \multirow{2}{*}{$.015^{\star}$} & \multirow{2}{*}{$1.26(1.01-1.58)$} \\
\hline & C/S (1317) & $507(38.5)$ & $810(61.5)$ & & \\
\hline \multirow{2}{*}{$\begin{array}{l}\text { Resuscitation } \\
\text { needed }\end{array}$} & Yes (962) & $543(56)$ & $419(44)$ & \multirow{2}{*}{$.001^{*}$} & \multirow[t]{2}{*}{$2.15(1.4-3.32)$} \\
\hline & No (1348) & $242(18)$ & $1106(82)$ & & \\
\hline \multirow{2}{*}{ SES } & <Average (1374) & $570(41.5)$ & $804(58.5)$ & \multirow{2}{*}{$.001^{*}$} & \multirow[t]{2}{*}{$2.95(1.7-5.1)$} \\
\hline & $\geq$ Average (936) & $215(23)$ & $721(77)$ & & \\
\hline \multirow{2}{*}{$\begin{array}{l}\text { Distance } \\
\text { Traveled(km) }\end{array}$} & $\leq 10(910)$ & $294(43.3)$ & $616(56.7)$ & \multirow{2}{*}{$.03^{*}$} & \multirow[t]{2}{*}{$2.5(1.7-2.9)$} \\
\hline & $>10(418)$ & $288(69)$ & $130(31)$ & & \\
\hline
\end{tabular}

*= Significant relation

$\mathrm{Cl}=$ Confidence interval

$\mathrm{SES}=$ Socio-economic status 
Table 3: Multivariate logistic regression for the analysis of the risk factors.

\begin{tabular}{|l|c|c|c|c|c|}
\hline Risk factors & B & SE & p value & OR & 95\% Cl \\
\hline Age(hours) & .810 & .351 & $.021^{*}$ & 2.25 & $1.13-4.47$ \\
\hline Gestational age(weeks) & .074 & .321 & .817 & .929 & $.495-1.74$ \\
\hline Place of delivery & .221 & .353 & .531 & 1.24 & $.625-2.49$ \\
\hline Mode of delivery & .859 & .252 & $.006^{*}$ & 1.35 & $1.18-2.12$ \\
\hline Resuscitation needed & .887 & .256 & $.001^{*}$ & 2.43 & $1.47-1.01$ \\
\hline Birth weight (gram) & .701 & .326 & $.032^{*}$ & 2.02 & $1.1-3.82$ \\
\hline Distance traveled & .109 & .255 & .669 & 1.11 & $.676-1.84$ \\
\hline Socio-economic status & 1.02 & .292 & $.001^{*}$ & 2.76 & $1.56-4.90$ \\
\hline
\end{tabular}

* $=$ Significant relation

\section{Discussion}

This study has been conducted to reveal the incidence and risk factors of hypothermia at admission in a NICU in Bangladesh. The incidence of admission hypothermia was $34 \%$. This high incidence of neonatal hypothermia at hospital obtained in this study is a matter of concern thus justifying the study.

Unlike the developed countries, developing countries with low resource settings, experience neonatal hypothermia even in healthy full term and normal-birth-weight infants. Many studies revealed increased incidence (11-85\%) of hypothermia among hospital and home-born newborn in South Asia, including Bangladesh, India, Pakistan, Bhutan and Nepal, as well as in developing countries with tropical climate $^{12}$. For example, in Nepal, $85 \%$ of newborns in a maternity hospital had a temperature $<36{ }^{\circ} \mathrm{C}$ within $2 \mathrm{~h}$ of birth ${ }^{13}$. In Ethiopia, Zambia and Zimbabwe, one-half to two-thirds of newborns evaluated were hypothermic ${ }^{12}$. The varying incidence of hypothermia may be due to differences in patients' selection.

A variety of articles are available from different countries about commonly used methods and devices for temperature measurements. Singh et.al. suggested a simple method for the assessment of a newborn baby's temperature by human touch ${ }^{14}$. Mizzi et.al. ${ }^{8}$ in their study used mercury in glass thermometer. In the current study we measured axillary temperature by the same device. Axillary recordings were chosen given the ease and safety of placement. WHO also recommends the use of this thermometer ${ }^{1,12}$. Accuracy of readings might have been slightly improved in rectal temperature measurement but there is a risk of injury.

In our study, hypothermia was highly prevalent among babies who presented within 24 hour of delivery. The observed high prevalence is, not surprising considering the fact that most of the neonates presenting to NICU are either PTVLBW or having birth related complications who need admission rapidly after birth. This observation was consistent with previous reports ${ }^{2,15,16}$. Manji KP et.al. also found a high incidence of hypothermia at 24 hours of age where they included both term and low birth weight infants in their study ${ }^{17}$.

The incidence of LBW in many developing countries is as high as $30 \%$ or more ${ }^{12}$. In Bangladesh the incidence of LBW is $36 \%{ }^{3}$. According to our study result, fifty seven percent neonates had low birth weight and of them $40 \%$ had hypothermia at admission. This study result is consistent with earlier reports $2,5,16,18$. The association of prematurity $(<37$ weeks) and hypothermia was not unexpected, because the physical characteristics of premature infants predispose to a mismatch between heat production and heat exchange with the ambient environment. Gestational age was found to be significant in bivariate analysis but non significant on logistic regression analysis.

Our study revealed a high incidence of hypothermia among the neonates born by caesarean section. This finding contradicts the usual observation of low incidence of hypothermia in institutional deliveries. Possible explanation may be the required resuscitation at birth when temperature control may not be properly taken care of.

Among the outborn (home or other hospital) babies in the current study, forty three percent had hypothermia (22\% among inborn). Neonates, who traveled more than 10 kilometers to reach to the NICU had significantly increased rate of hypothermia (univariate analysis). In Bangladesh neither in-utero referral nor transportation to the hospital with proper thermal care is practiced. Neonates are brought to the hospital in someone's arm without proper wrapping. They are often carried to the hospital by an open vehicle or even by rickshaw. Due to this poor transportation system, sick outborn babies are additionally exposed to the risk of hypothermia. Evidence from studies on neonatal transport between hospital to 
hospital or between wards within hospitals suggests that even in controlled settings, risk of hyothermia during transport is high ${ }^{18}$. It has been showed that the severity of hypothermia in newborns was highly correlated with the length of time it took to transfer and admit ${ }^{19}$. Similar findings were observed in rural Nepal ${ }^{20}$, India ${ }^{21}$ and Brazil'22.

It is already known that out-born babies become significantly hypothermic but the high (22\%) incidence of hypothermia among in-born babies in our study is alarming. Temperature maintenance protocol might not be followed during the stay of the neonate in obstetric ward. Moreover, most inborn babies brought to NICU are high-risk and often critically ill due to perinatal asphyxia, infections and respiratory distress ${ }^{2,5,12}$.

In concordance with previous reports ${ }^{2,5,21}$ the presence of asphyxia was a strong determinant of hypothermia at admission in the current study. There may be inadequate temperature maintenance of babies during resuscitation among out born as well as inborn neonates. Moreover, the hypoxic-ischemic effects of asphyxia disturb both central and peripheral thermoregulatory mechanisms and might cause hypothermia.

We found a significant association between incidence of hypothermia and monthly income of the family. Neonates who belong to poor and below average socio-economic status had serious morbidity and associated hypothermia. F Zayeri et.al. ${ }^{5}$ and BA Doctor et.al. ${ }^{23}$ in Iran and Okogbo ME et.al. ${ }^{24}$ in Nigeria have shown a significant association between neonatal hypothermia and inadequate clothing after delivery and low socioeconomic status of the mother. Mullany et al. ${ }^{20}$ and Younis $\mathrm{K}$ et.al. ${ }^{25}$ also showed similar findings. Younis $\mathrm{K}$ et al also showed that mother's education along with socioeconomic status play an important role as determinants of neonatal morbidity like low birth weight and NICU admission.

Lastly, this study finding helps us to understand the high incidence and modifiable risk factors for neonatal hypothermia in our set up. It can be emphasized that there is an urgent need to increase awareness about the risk factors for hypothermia among all levels of health care personnel, as well as families. The maintenance of temperature should be emphasized during resuscitation and during obstetric ward stay with the mother. Neonatal transport vehicles with transport incubators should be made available in hospitals and outreach centers.

\section{Conclusion}

Incidence of admission hypothermia among neonates in our NICU was $34 \%$. Independent risk factors are resuscitation at birth, very low birth weight, caesarean section delivery, age less than 24 hours and poor socio-economic condition. Proper thermal care should be provided for neonates at home, hospitals and transports.

Acknowledgement: We express our gratitude to Nurses and Internal medical officer (IMO)s of EMCH $\mathrm{NICU}$, who has examined the neonates and helped us for collecting data.

Funding: None

Conflict of Interest: None

Permission from IRB: Yes

\section{References}

1. WHO. Maternal and Safe Motherhood Programme. Thermal Control of the Newborn: a Practical Guide 1993; Geneva, Switzerland.

2. Ogunlesi TA, Ogunfowora OB, Adekanmbi FA, Fetuga BM, Olanrewaju DM. Point-of-admission hypothermia among high-risk Nigerian newborns. BMC Pediatr 2008; 8: 40

3. Ministry of Health and Family welfare. Banglagladesh. National Neonatal health strategy and guideline, 2009.

4. Darmstadt GL, Bhutta ZA, Cousens S, Adam T, Walker N, De Bernis L. Evidence-based, costeffective interventions: how many newborn babies can we save? Lancet 2005;365:977-88.

5. Zayeri F, Kazemnejad A, Ganjali M, G. Babaei G, Nayeri F. Incidence and risk factors of neonatal hypothermia at referral hospitals in Tehran, Islamic Republic of Iran. Eastern Medit Health J 2007;13:1308-318.

6. Chance GW, Matthew JD, Williams G, Cunningham K. Neonatal transport: a controlled study of skilled assistance. J Pediatr 1978;93:662-66.

7. World Health Organization. Thermal protection of the newborn: a practical guide. WHO; (WHO/FHF/ MSM/97.2): Geneva, 1997.

8. Mizzi J, Muskat RV. Hypothermia in the early neonatal period: follow-up study. Malta Med J 2007;19:34-37.

9. Darmstadt GL, Saha SK. Traditional Practice of Oil Massage of Neonates in Bangladesh. $J$ Health Popul Nutr 2002;20:184-88.

10. Winch PJ, Alam MA, Akther A, Afroz D, Ali NA, Ellis AA et al. Local understandings of vulnerability and protection during the neonatal period in Sylhet district, Bangladesh: a qualitative study. Lancet 2005;366:478-85.

11. Bangladesh Bureau of Statistics. Preliminary report of the household income and expenditure survey 2011, Dhaka, Bangladesh. 
12. Kumar V, Shearer JC, Kumar A, Darmstadt GL. Neonatal hypothermia in low resource settings: a review. J Perinatol 2009;29:401-12.

13. Johanson RB, Malla DS, Tuladhar C, Amatya M, Spencer SA, Rolfe P. A survey of technology and temperature control on a neonatal unit in Kathmandu, Nepal. J Trop Pediatr 2001;39:4-10.

14. Singh M, Rao G, Malhotra AK. Assessment of newborn baby's temperature by human touch: a potentially useful primary care strategy. Indian Pediatr 1992; 29:449-52.

15. Bang AT, Reddy HM, Baitule SB, Deshmukh MD, Bang RA. The incidence of morbidities in a cohort of neonates in rural Gadchiroli, India: seasonal and temporal variation and a hypothesis about prevention. J Perinatol 2005;25:S18-28.

16. Byaruhanga RA, Bergstrom A, Okong P: Neonatal hypothermia in Uganda: prevalence and risk factors. J Trop Paediatr 2005;51:212-15.

17. Manji KP, Kisenge R: Neonatal hypothermia on admission to a Special Care Unit in Dar-es-Salaam, Tanzanian a cause for concern. Cent Afr J Med 2003;49:23-27.

18. Laptook AR, Salhab W, Bhaskar B. Admission temperature of low birth weight infants: predictors and associated morbidities. Pediatrics 2007;119:e643-49
19. Bowmen ED, RND Roy. Control of temperature during newborn transport: An old problem with new difficulties. J Paediatr Child Heaith 1997;33:398-01.

20. Mullany LC, Katz J, Khatry SK, LeClerq SC, Darmstadt GL, Tielsch JM. Neonatal hypothermia and associated risk factors among newborns of southern Nepal. BMC Medicine 2010;8:43.

21. Kaushik SL, Grover N, Parmar VR, Kaushik R, Gupta AK. Hypothermia in Newborns at Shimla. Indian Pediatr 1998;35:652-56.

22. da Mota Silveira SM, de Mello MJG, de Arruda Vidal S, de Frias PG, Cattaneo A. Hypothermia on admission: a risk factor for death in newborns referred to the Pernambuco Institute of Mother and Child Health. 2003;49:115-20.

23. Doctor BA, O'Riordar MA, Kirchna HL, Shah D, Hack M. Perinatal correlates and neonatal outcomes of small for gestational age infants born at term gestation. Am J Obstetr Gynaecol 2001;185:652-59.

24. Okogbo ME, Familusi JB. Low birth weight and its correlates among Nigerian twins. Afr J Med Med Sci 1997;26:5-7.

25. Yunis K, Beydoun H, Khogali M, Alameh M, Tamim $\mathrm{H}$; National Collaborative Perinatal Neonatal Network. Low socioeconomic status and neonatal outcomes in an urban population in a developing country. J Matern Fetal Neonatal Med 2003;14:3384. 